\title{
Ruptured arterial aneurysm in Wegener's granulomatosis: a case report
}

\author{
A. Gravos ${ }^{1 *}$, K. Katsifa ${ }^{1}$, P. Tselioti ${ }^{1}$, V. Grammatikopoulou ${ }^{1}$, K. Sakellaridis ${ }^{1}$, S. Kanakaki ${ }^{1}$, C. Tsapas ${ }^{1}$, A. Destounis ${ }^{1}$, \\ H. Moschouris², I. Athanasiadou' ${ }^{1}$ F. Chatzivasiloglou' ${ }^{1}$ E. Ivanova ${ }^{1}$ and A. Prekates ${ }^{1}$
}

\begin{abstract}
Background: Aneurysm formation is a possible, but rare, complication of granulomatosis with polyangiitis, known as Wegener's granulomatosis. Urgent diagnosis and therapy is very important because a ruptured aneurysm could be life threatening.

Case presentation: We, therefore, present the case of a 63-year-old Greek man who was diagnosed with granulomatosis with polyangiitis and retroperitoneal hematoma due to ruptured aneurysm in renal artery and upper pancreaticoduodenal artery. His clinical course was complicated by acute renal failure and acute respiratory failure due to alveolar hemorrhage. Emergency coil embolization was performed. Postembolization recovery was uneventful; no bleeding occurred. The patient underwent mechanical ventilation and continuous veno-venous hemofiltration and received combined immunosuppression and supportive therapy, but eventually died 30 days after admission to hospital from severe septic shock and multiple organ failure.
\end{abstract}

Conclusion: Endovascular treatment is the therapy of choice, especially for patients with ruptured aneurysms that are hemodynamically stable. Early diagnosis is very important, as urgent embolization and early initiation of immunosuppression therapy are the treatment of choice.

Keywords: Granulomatosis with polyangiitis, Immunosuppression therapy, Aneurysm

\section{Background}

Wegener's granulomatosis, nowadays known as granulomatosis with polyangiitis (GPA), is a multisystemic disease characterized by granulomatous and systemic necrotizing vasculitis. Inflammation mainly affects the small-to-medium-sized arteries of the kidneys, upper airways, and the lungs [1].

Granulomatosis with polyangiitis (GPA) is an immunemediated and complex disorder in which tissue injury results from the interaction of a highly specific immune response and an initiating inflammatory event. Part of this response is directed against previously shielded

\footnotetext{
*Correspondence: athgravos@gmail.com

${ }^{1}$ Intensive Care Unit (ICU), Tzaneio General Hospital of Piraeus, Dodonis 26, Kamatero, PC: 13451, Greece
}

Full list of author information is available at the end of the article epitopes of neutrophil granule proteins, leading to autoantibodies known as antineutrophil cytoplasmic autoantibodies (ANCA) [2]. Approximately $85 \%$ of patients with GPA are ANCA positive. The most commonly identified and evaluated autoantibodies in GPA recognize the autoantigens proteinase 3 (PR3-ANCA), observed in $70-80 \%$ of patients, and myeloperoxidase (MPO-ANCA), observed in 10\% of patients [3].

In the early stages of ANCA-associated vasculitis, endothelial cells may recruit inflammatory cells and enhance their adhesion to sites of vascular injury. This could lead to aneurysm formation in these arteries [4]. Formation of aneurysms is a very rare complication of GPA, and only a few cases [5-24] have been reported in the literature. We, therefore, present a case and therapeutic interventions of arterial aneurysms in GPA. original author(s) and the source, provide a link to the Creative Commons licence, and indicate if changes were made. The images or other third party material in this article are included in the article's Creative Commons licence, unless indicated otherwise in a credit line to the material. If material is not included in the article's Creative Commons licence and your intended use is not permitted by statutory regulation or exceeds the permitted use, you will need to obtain permission directly from the copyright holder. To view a copy of this licence, visit http://creativecommons.org/licenses/by/4.0/. The Creative Commons Public Domain Dedication waiver (http://creativeco mmons.org/publicdomain/zero/1.0/) applies to the data made available in this article, unless otherwise stated in a credit line to the data. 


\section{Case presentation}

\section{Patient information}

A 63-year-old Greek man, active smoker, was admitted to the emergency department with a 2-month history of dyspnea and presented with acute abdominal pain. One month ago, he was diagnosed with GPA by lung biopsy and laboratory testing and was receiving low-dose dexamethasone (15 mg/day). His other medical and family history was unremarkable. He was not using anticoagulant agents.

\section{Clinical findings}

On physical examination, his blood pressure was $110 / 70 \mathrm{mmHg}$, pulse rate 80 beats/minute, and respiration rate 20 breaths/minute, and he was afebrile. His height was $170 \mathrm{~cm}$ and weight $70 \mathrm{~kg}$. His heart sounds were regular without any murmur, and his respiratory sounds were clear. He had abdominal dilatation with diffuse sensitivity to palpation and dullness on percussion. There were no inflamed joints, nasopharyngeal abnormalities, or dermatologic manifestations. On admission, there was no need for intubation and mechanical ventilation, and the patient was hemodynamically stable and with normal neurological examination.

\section{Diagnostic assessment}

Complete laboratory testing and blood gases were obtained, and urgent computed tomography (CT) scan of the lungs, brain, and upper and lower abdomen was performed. Chest X-ray (CXR) showed an infiltrative shadow in the upper left lobe (Fig. 1a), while CT scan showed multiple intraparenchymal cavitated nodules in the left lung (Fig. 1b) and a large retroperitoneal hematoma and multiple aneurysms of the renal, hepatic, and pancreaticoduodenal arteries (Fig. 1c). There were no other brain or chest aneurysms, as confirmed by wholebody CT angiography.

Laboratory tests showed: leukocyte count: $16 \times 10^{3} / \mu \mathrm{L}$ (80\% neutrophils, $10 \%$ lymphocytes, $5 \%$ monocytes, and $2 \%$ eosinophils); hemoglobin $7.2 \mathrm{~g} / \mathrm{dL}$; hematocrit $21.1 \%$; platelet count $235 \times 10^{3} / \mu \mathrm{L}$; C-reactive protein $46 \mathrm{mg} /$ $\mathrm{dL}$; urea $236 \mathrm{mg} / \mathrm{dL}$; serum creatinine $(\mathrm{SCr}) 7.6 \mathrm{mg} / \mathrm{dL}$ (2 months prior to admission, his SCr level was $0.7 \mathrm{mg} /$ $\mathrm{dL}$ ); and albumin: $2.3 \mathrm{~g} / \mathrm{dL}$. His liver enzyme levels and electrolytes were normal. His erythrocyte sedimentation rate (ESR) was $122 \mathrm{~mm} /$ hour. Urinalysis showed protein of $2+$ and blood of $2+$, but without red blood cell casts or dysmorphic red blood cells. Proteinase-3 antineutrophil cytoplasmic antibody (PR3-ANCA), c-ANCA, and antinuclear antibody were positive, while antiglomerular basement antibody (GBM) and myeloperoxidase antineutrophil cytoplasmic antibody (MPO) were negative. The
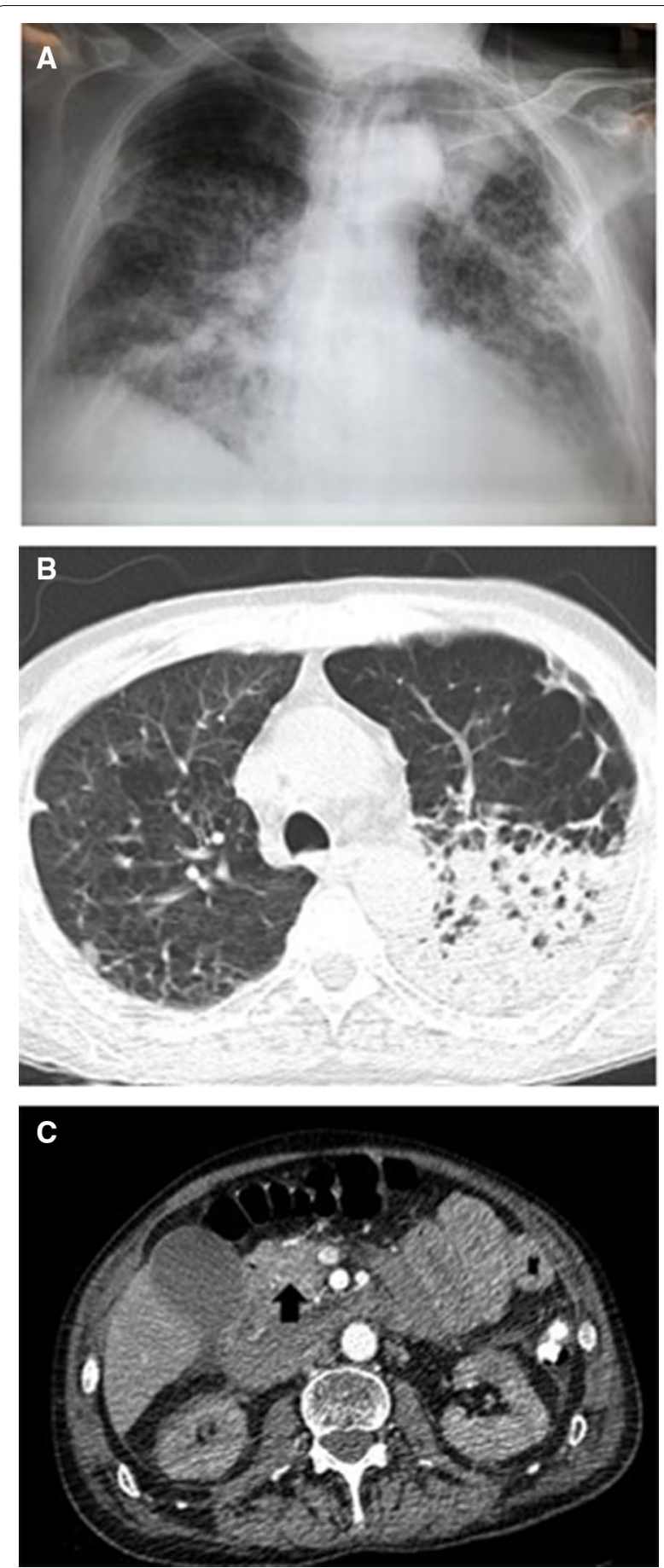

Fig. 1. a CXR of the patient on admission showing infiltrative shadows in both lungs, especially in the left upper lobe. b Chest CT scan showing multiple intraparenchymal cavitated nodules in the left lung. c Abdominal CT scan showing a large retroperitoneal hematoma (arrow) and multiple aneurysms of the renal, hepatic, and pancreaticoduodenal arteries 
serum total complement and complement 3 and 4 levels and serum protein electrophoresis were within normal limits. Viral serology for human immunodeficiency virus (HIV), hepatitis B virus, and hepatitis $C$ virus was normal.

\section{Therapeutic interventions}

Automatic rupture of these aneurysms with concomitant retroperitoneal hematoma was suspected, and urgent angiography of the celiac artery and renal arteries was performed. Angiography showed multiple aneurysms of the hepatic, renal, and pancreaticoduodenal arteries and embolization of the pancreaticoduodenal arteries was performed, as these arteries were the suspected cause of the hematoma (Fig. 2).

The following day of embolization, the patient deteriorated and was intubated because of acute respiratory failure and was transferred to the ICU. His respiratory failure was attributed to alveolar hemorrhage, as confirmed by bronchoscopy and bronchoalveolar lavage. He did not develop pancreatitis after the embolization. In the ICU, the patient was hemodynamically stable, on mechanical ventilation, and sedated. His blood gases improved immediately after intubation. Due to acute renal failure, he was placed in continuous veno-venous hemofiltration (CVVHDF) and received pulse therapy with methylprednisolone $1 \mathrm{~g} /$ day for 3 days followed by maintenance therapy with prednisolone $50 \mathrm{mg} /$ day and $700 \mathrm{mg}$ cyclophosphamide pulses, after proper hydration, two times on a 2-week basis. The daily dose of prednisone was tapered gradually.

\section{Follow-up and outcomes}

The patient deteriorated gradually, despite the initial improvement and the early and combined immunosuppression and supportive therapy. He was subjected to tracheostomy on the 15th day of admission, but developed severe thrombocytopenia and neutropenia, attributed to cyclophosphamide. Blood cultures on the 20th day revealed Acinetobacter baumannii, for which he received combined antibiotic therapy. His clinical and hemodynamic condition and results of laboratory and blood gas testing deteriorated gradually and finally died on the $30^{\text {th }}$ day of admission from severe septic shock and multiple organ failure.

\section{Discussion}

In January 2011, the Boards of Directors of the American College of Rheumatology (ACR), the American Society of Nephrology (ASN), and the European League Against Rheumatism (EULAR) recommended that the name "Wegener's granulomatosis" be changed to "granulomatosis with polyangiitis," abbreviated as GPA. This change is a plan to gradually shift from honorific eponyms to a disease-descriptive or etiology-based nomenclature. Antineutrophil cytoplasmic autoantibody (ANCA)-associated vasculitis (AAV) includes microscopic polyangiitis (MPA), renal-limited vasculitis (RLV), eosinophilic granulomatosis with polyangiitis (EGPA, Churg-Strauss), and granulomatosis with polyangiitis (GPA). All are associated with ANCA and have similar features on renal histology $[25,26]$.

GPA is a multisystemic, but rare, disease characterized by granulomatous and systemic necrotizing vasculitis. The expression of glycoprotein enzymes, such as PR3 on the surface of cytokine-primed neutrophils, is the key to the pathogenesis of GPA. PR3-ANCA then binds to this antigen and activates neutrophils. This results in cytotoxicity to vascular endothelial cells via release of proinflammatory cytokines and lytic
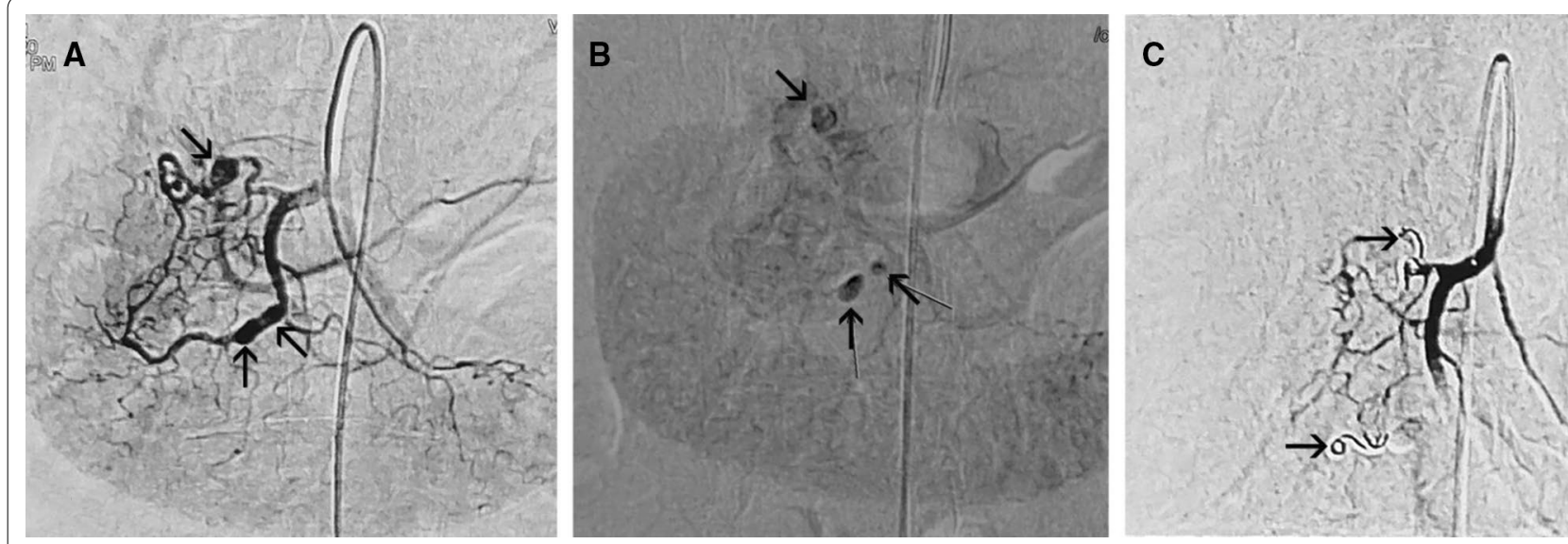

Fig. 2. Digital subtraction angiograms (DSAs, $\mathbf{A}$ arterial, $\mathbf{B}$ parenchymal phase) showing three pseudoaneurysms (arrows) of the pancreaticoduodenal arteries. DSA postembolization (C), with microcoils (arrows) and Gelfoam shows obliteration of the pseudoaneurysms 
enzymes. GPA affects mainly the medium and small arteries of the kidneys and the respiratory tract $[27,28]$. Inflammation can also lead to aneurysm formation in larger arteries, but aneurysm formation is a very unusual complication. About 20 cases [5-24] are described with large-vessel aneurysms in patients with GPA.

A review in 2017 [5] revealed that arterial aneurysms were diagnosed within 1 month from disease onset and were observed more commonly in men. Most patients had symptoms of aortitis and ischemia, such as abdominal and back pain. Most cases were large-vessel aneurysms, medium-vessel aneurysms, branches of the celiac axis, and branches of the renal artery. Rupture is not a rare complication, requiring urgent recognition and treatment either with embolization or surgery [5].

Treatment involves the combination of endovascular and surgical interventions with immunosuppressive agents such as high-dose methylprednisolone, cyclophosphamide, and/or rituximab to prevent aneurysm rupture and control of hemorrhage [29, 30]. Our patient was treated by endovascular intervention combined with high-dose methylprednisolone and cyclophosphamide, but finally died due to septic shock from Acinetobacter baumannii.

Initial immunosuppression therapy in granulomatosis with polyangiitis (GPA) typically consists of high-dose glucocorticoids combined with either cyclophosphamide or rituximab. Some studies have described the use of both cyclophosphamide and rituximab for initial therapy (rather than using one of these two agents), although this approach is controversial. Some patients with severe disease may benefit from the addition of plasma exchange, especially those with concurrent anti-GBM autoantibody disease and pulmonary hemorrhage [31].

The mortality rate in untreated generalized GPA is about $90 \%$ at 2 years, usually due to respiratory or renal failure. Thus, the use of aggressive initial immunosuppression is justified. The introduction of initial therapy with cyclophosphamide and glucocorticoids has markedly diminished the mortality [32].

\section{Conclusions}

We present a rare case of a life-threatening ruptured aneurysm in a patient with GPA. Clinicians should be aware of this rare complication of GPA, which can be the cause of retroperitoneal hematoma. Accurate diagnosis in combination with early immunosuppression and embolization therapy should be performed. Endovascular intervention is the treatment of choice, accompanied by surgical therapy if embolization fails or is not available.

\section{Abbreviations}

ICU: Intensive care unit; GPA: Granulomatosis with polyangiitis; ANCA: Antineutrophil cytoplasmic autoantibodies; PR3-ANCA: Proteinase 3 antineutrophil cytoplasmic autoantibodies; MPO-ANCA: Myeloperoxidase antineutrophil cytoplasmic autoantibodies; CT: Computed tomography; CXR: Chest X-ray; ESR: Erythrocyte sedimentation rate; GBM: Antiglomerular basement antibody; CVVHDF: Continuous veno-venous hemofiltration; ACR: American College of Rheumatology; ASN: American Society of Nephrology; EULAR: European League Against Rheumatism; AAV: ANCA-associated vasculitis; MPA: Microscopic polyangiitis; RLV: Renal-limited vasculitis; EGPA: Eosinophilic granulomatosis with polyangiitis.

\section{Acknowledgements \\ Not applicable.}

\section{Authors' contributions}

AG is the corresponding author who wrote this case report and collected the data. KK, PT, and VG participated in the sequence alignment. KS and AD participated in the sequence alignment and corrected the manuscript. SK and CT participated in the design of the study. IA, FC, and El participated in the sequence alignment. AP conceived of the study, participated in its design and coordination, and helped to draft the manuscript. All authors read and approved the final manuscript.

\section{Funding}

Not applicable.

Availability of data and materials

Data supporting our findings can be found in the patient's electronic file.

\section{Declarations}

Ethics approval and consent to participate

The Ethics Committee of Tzaneio General Hospital of Piraeus approved and gave consent for this study. Written informed consent was obtained from the patient's family to participate. We have also obtained consent to publish and report individual patient data.

\section{Consent for publication}

Written informed consent was obtained from the patient's family for publication of this case report and any accompanying images. A copy of the written consent is available for review by the Editor-in-Chief of this journal.

\section{Competing interests}

The authors declare that they have no competing interests.

\section{Author details}

${ }^{1}$ Intensive Care Unit (ICU), Tzaneio General Hospital of Piraeus, Dodonis 26, Kamatero, PC: 13451, Greece. ${ }^{2}$ Radiology Department, Tzaneio General Hospital of Piraeus, Kamatero, Greece.

Received: 12 May 2020 Accepted: 14 June 2021

Published online: 12 July 2021

\section{References}

1. Jenette JC, Falk RJ. Small-vessel vasculitis. N Engl J Med. 1997;337:1512-23.

2. Jennette JC, Falk RJ. Pathogenesis of antineutrophil cytoplasmic autoantibody-mediated disease. Nat Rev Rheumatol. 2014;10:463.

3. Bossuyt X, Cohen Tervaert JW, Arimura Y, et al. Position paper: revised 2017 international consensus on testing of ANCAs in granulomatosis with polyangiitis and microscopic polyangiitis. Nat Rev Rheumatol. 2017; 13(11):683-92.

4. Berger SP, Seelen MA, Hiemstra PS, et al. Proteinase 3, the major autoantigen of Wegener's granulomatosis, enhances IL-8 production by endothelial cells in vitro. J Am Soc Nephrol. 1996;7:694. 
5. Toshihide Tomosugi, Takuji Takahashi, Yoshihisa Kawase, et al. Accessory left gastric artery aneurysms in granulomatosis with polyangiitis: a case report and literature review. Nagoya J. Med. Sci, 2017;79. $75 \sim 83$.

6. den Bakker MA, Tangkau PL, Steffens TW, et al. Rupture of a hepatic artery aneurysm caused by Wegener's granulomatosis. Pathol Res Pract. 1997;193:61-6.

7. Baker SB, Robinson DR. Unusual renal manifestations of Wegener's granulomatosis. Report of two cases. Am J Med, 1978; 64: 883-889.

8. Moutsopoulos HM, Avgerinos PC, Tsampoulas CG, et al. Selective renal angiography in Wegener's granulomatosis. Ann Rheum Dis. 1983:42:192-5.

9. Sieber SC, Cuello B, Gelfman NA, et al. Pulmonary capillaritis and glomerulonephritis in an antineutrophil cytoplasmic antibody-positive patient with prior granulomatous aortitis. Arch Pathol Lab Med. 1990;114:1223-6.

10. Aoki N, Soma K, Owada T, et al. Wegener's granulomatosis complicated by arterial aneurysm. Intern Med. 1995;34:790-3.

11. Blockmans $D$, Baeyens $H$, Van Loon $R$, et al. Periaortitis and aortic dissection due to Wegener's granulomatosis. Clin Rheumatol. 2000;19:161-4.

12. Shitrit $D$, Shitrit $A B$, Starobin $D$, et al. Large vessel aneurysms in Wegener's granulomatosis. J Vasc Surg. 2002;36:856-8.

13. Senf R, Jurgensen JS, Teichgraber $U$, et al. Ruptured arterial aneurysm of the kidney in a patient with Wegener's granulomatosis. Nephrol Dial Transplant. 2003;18:2671-3.

14. Famularo G, De Cata A, Bracci M, et al. Fatal rupture of an inflammatory arterial aneurysm in a patient with Wegener's granulomatosis. Scand J Rheumatol. 2004;33:277-9.

15. Takei $H$, Komaba Y, Kitamura $H$, et al. Aneurysmal subarachnoid hemorrhage in a patient with Wegener's granulomatosis. Clin Exp Nephrol. 2004;8:274-8.

16. Carels T, Verbeken E, Blockmans D. p-ANCA-associated periaortitis with histological proof of Wegener's granulomatosis: case report. Clin Rheumatol. 2005;24:83-6.

17. Arlet JB, Le Thi HD, Marinho A, et al. Arterial aneurysms in Wegener's granulomatosis: case report and literature review. Semin Arthritis Rheum. 2008;37:265-8.

18. Minnee RC, van den Berk GE, Groeneveld JO, et al. Aortic aneurysm and orchitis due to Wegener's granulomatosis. Ann Vasc Surg. 2009;23(786):e15-9.

19. Durai $R$, Agrawal $R$, Piper $K$, et al. Wegener's granulomatosis presenting as an abdominal aortic aneurysm: a case report. Cases J. 2009;2:9346.

20. Luebke T, Aleksic M, Brunkwall J. Superficial femoral artery aneurysm: a rare complication of Wegener granulomatosis. Vascular. 2009;17:213-7.
21. Unlu C, Willems M, Ten Berge IJ, et al. Aortitis with aneurysm formation as a rare complication of Wegener's granulomatosis. J Vasc Surg. 2011;54:1485-7.

22. Musuruana JL, Cavallasca JA, Berduc J, et al. Coronary artery aneurysms in Wegener's granulomatosis. Joint Bone Spine. 2011;78:309-11.

23. Onodera $\mathrm{H}$, Hiramoto J, Morishima $\mathrm{H}$, et al. Treatment of an unruptured fusiform aneurysm of the internal carotid artery associated with Wegener's granulomatosis by endovascular balloon occlusion. Case report. Neurol Med Chir (Tokyo). 2012;52:216-8.

24. Ohta N, Waki T, Fukase $\mathrm{S}$, et al. Aortic aneurysm rupture as a rare complication of granulomatosis with polyangiitis: a case report. J Med Case Rep. 2013;26:202.

25. Falk RJ, Gross WL, Guillevin L, et al. Granulomatosis with polyangiitis (Wegener's): an alternative name for Wegener's granulomatosis. Arthritis Rheum. 2011;63:863.

26. Jennette JC, Falk RJ, Bacon PA, et al. 2012 revised International Chapel Hill Consensus Conference Nomeclature of Vasculitides. Arthritis Rheum. 2013;65:1-11.

27. Savage CO, Pottinger BE, Gaskin G, et al. Autoantibodies developing to myeloperoxidase and proteinase 3 in systemic vasculitis stimulate neutrophil cytotoxicity toward cultured endothelial cells. Am J Pathol. 1992;141:335-42.

28. Kessenbrock K, Krumbholz M, Schonermarck U, et al. Netting neutrophils in autoimmune small-vessel vasculitis. Nat Med. 2009;15:623-5.

29. de Groot K, Harper L, Jayne DR, et al. Pulse versus daily oral cyclophosphamide for induction of remission in antineutrophil cytoplasmic antibody-associated vasculitis: a randomized trial. Ann Intern Med. 2009;150:670-80.

30. Stone JH, Merkel PA, Spiera R, et al. Rituximab versus cyclophosphamide for ANCA-associated vasculitis. N Engl J Med. 2010;363:221-32.

31. Yates M, Watts RA, Bajema IM, et al. EULAR/ERA-EDTA recommendations for the management of ANCA-associated vasculitis. Ann Rheum Dis. 2016;75:1583.

32. Flossmann $\mathrm{O}$, Berden $\mathrm{A}$, de Groot $\mathrm{K}$, et al. Long-term patient survival in ANCA-associated vasculitis. Ann Rheum Dis. 2011;70:488

\section{Publisher's Note}

Springer Nature remains neutral with regard to jurisdictional claims in published maps and institutional affiliations.
Ready to submit your research? Choose BMC and benefit from:

- fast, convenient online submission

- thorough peer review by experienced researchers in your field

- rapid publication on acceptance

- support for research data, including large and complex data types

- gold Open Access which fosters wider collaboration and increased citations

- maximum visibility for your research: over 100M website views per year

At BMC, research is always in progress.

Learn more biomedcentral.com/submissions 